\title{
Study of the Bandgap of Synthesized Titanium Dioxide Nanoparticules Using the Sol-Gel Method and a Hydrothermal Treatment
}

\author{
Sergio Valencia, Juan Miguel Marín and Gloria Restrepo* \\ Applied Physical Chemistry Processes, University of Antioquia, Medellin, Colombia
}

\begin{abstract}
In this work optical properties of titanium dioxide nanoparticles were studied. Titanium dioxide nanoparticles were synthesized by the sol-gel method followed by a hydrothermal treatment using tetraisopropyl orthotitanate (TIOT) and 2-propanol. The synthesized samples were characterized by X-ray diffraction (XRD), UV-Vis diffuse reflectance spectroscopy (UV/DRS) and nitrogen adsorption-desorption methods. The bandgap energy was obtained using the Kubelka-Munk reemission function. The catalyst synthesized with a molar ratio of $\mathrm{R}_{1}$ (water/TIOT) $=3.5$ and $\mathrm{R}_{2}$ (2-propanol/TIOT) $=15$ has a predominately anatase phase. It also has a high photo degradation of methyl orange compared to $\mathrm{TiO}_{2} \mathrm{Degussa}$ P-25. A shift band gap energy of 3.27 was observed.
\end{abstract}

Keywords: Titanium dioxide, hydrothermal treatment, sol-gel method, band gap.

\section{INTRODUCTION}

Titanium oxide $\left(\mathrm{TiO}_{2}\right)$ is a material with wide application due to its optical and electronic properties. It is used as an ingredient in sunscreen lotions and food products, as a pigment in paints and as semiconductors in the photocatalytic degradation of organic compounds [1]. In $\mathrm{TiO}_{2}$, the crystalline phase, the composition and the surface states strongly affect the electronic structure and the charge properties [2]. The photocatalytic activity of $\mathrm{TiO}_{2}$ depends on its present phase. There are three crystalline forms of $\mathrm{TiO}_{2}$ : anatase, rutile and brookite. Anatase phase is metastable and has the greater photocatalytic activity; rutile has a high chemical stability but is less active $[3,4]$. Besides, some $\mathrm{TiO}_{2}$ with a large quantity of anatase and a small quantity of rutile exhibits a higher photocatalitic activity than in the pure anatase or rutile phases [2,5]. The absorption spectrum of a semiconductor defines its possible uses. The useful semiconductors for photocatalysis have a bandgap comparable to the energy of the photons of visible or ultraviolet light, having a value of $\mathrm{E}_{\mathrm{g}}<3.5 \mathrm{eV}$. The majority of authors have determined that in $\mathrm{TiO}_{2}$ the rutile has a direct band gap of $3.06 \mathrm{eV}$ and an indirect one of $3.10 \mathrm{eV}$ and the anatase has only an indirect band gap of $3.23 \mathrm{eV}[6,7]$. However, Reddy's work [1] shows that a bandgap of anatase phase from the plot for indirect transition are quite low (2.95 $-2.98 \mathrm{eV}$ ), which led them, contrary to the other authors, to conclude that the direct transition is more favorable for $\mathrm{TiO}_{2}$ nanoparticles with anatase phase. There have been reported values in the literature from 2.86 to $3.34 \mathrm{eV}$ for the anatase phase, the differences being attributed to variations in the stoichiometric of the synthesis, the impurities content, the crystalline size and the type of electronic transition [8,9]. In this work the optical properties are evaluated in context of the bandgap of the synthesized $\mathrm{TiO}_{2}$ samples with the sol-gel

*Address correspondence to this author at the Applied Physical Chemistry Processes, University of Antioquia, Medellin, Colombia; Tel: 574 2196578; Fax: 574 2196543; E-mail: gloma@udea.edu.co method and the hydrothermal treatment, using a crystallization temperature of $200^{\circ} \mathrm{C}$ for 2 hours, and TIOT as precursor $[8,10-14]$. The bandgap was calculated by means of the reflectance diffusion technique, which shows an abrupt increase in the absorbance of the longitude or the wave corresponding to the energy of the prohibited band.

\section{MATERIALS AND METHODS}

\subsection{Reactives}

Teraisopropyl orthotitanate (TIOT), 2-propanol and hydrochloric acid are from Merck, methyl orange from Carlo Erba, titanium dioxide P-25 Degussa and Milli-q water.

\subsection{Preparation of the Samples}

The titanium precursor TIOT and water were added dropwise into the 2-propanol solvent, continuously stirring for 2 hours, after that 3 drops of $\mathrm{HCl} 3 \mathrm{M}$ was added. For the crystallization under autogenous pressure the solution obtained was put in a steel-teflon reactor and heated to $200^{\circ} \mathrm{C}$ for 2 hours, after which the sample was filtered and washed with $30 \mathrm{~mL}$ of 2-propanol and was dried at $100^{\circ} \mathrm{C}$ for 1 hour. In order to study the effect of some variables on the synthesis of $\mathrm{TiO}_{2}$ a $3^{2}$ factorial design was used, with $\mathrm{R}_{1}$ (water/TIOT) and $\mathrm{R}_{2}$ (water/TIOT) as factors with the levels $2.85,3.5$, 60 and 10, 15, 20, respectively (Table $\mathbf{1}$ ).

\subsection{Characterization}

XRD analysis was performed using an $\mathrm{x}$-ray diffractometer (Rigaku Miniflex) with $\mathrm{Cu}-\mathrm{K} \alpha$ radiation in $2 \theta$ range from $10^{\circ}$ to $60^{\circ}$; the reflectance diffusion spectrum UV-Vis (UV/DRS) was obtained using a UV-Vis Evolution 600 spectrometer, a thermo Electron Corporation with a reflectance diffuse accessory; the superficial area of Brunauer-Emmett-Teller was determined using a Gemini V Miromerities.

\subsection{Photocatalytic Activity Measurements}

In order to evaluate the photocatalytic activity of each of the synthesized $\mathrm{TiO}_{2}, 37.5 \mathrm{mg}$ of $\mathrm{TiO}_{2}$ was added in $250 \mathrm{~mL}$ 
of methyl orange solution with initial concentration of 20 ppm for a $\mathrm{TiO}_{2}$ amount of $0.15 \mathrm{~g} / \mathrm{L}$. A test of photolysis for one hour showed no degradation. The photocatalytic experiments were began after the adsorption equilibrium was obtained, in one hour. After that the lamps were turned on for 7 hours, samples were withdrawn each hour and analyzed by UV-Vis spectrometer using a wavelength of $464 \mathrm{~nm}$. A BLB lamp of $25 \mathrm{~W} / \mathrm{cm}^{2}$ with emissions between 300 and 400 $\mathrm{nm}$ with a maximum at $360 \mathrm{~nm}$ was used as irradiation supply. All experiments were carried out with an aeration system in order to maintain the reaction system saturated with oxygen.

Table 1. $3^{2}$ Factorial Designs for the $\mathrm{TiO}_{2}$ Synthesis by SolGel Method and Hydrothermal Technique at $200^{\circ} \mathrm{C}$ for 2 Hours, Using TIOT as Precursor

\begin{tabular}{|c|c|c|}
\hline Experiment & $\mathbf{R}_{\text {1(water/TIOT) }}$ & $\mathbf{R}_{\text {2(2-propanol/TIOT) }}$ \\
\hline \hline M1 & 2.85 & 10.0 \\
\hline M2 & 2.85 & 15.0 \\
\hline M3 & 2.85 & 20.0 \\
\hline M4 & 3.50 & 10.0 \\
\hline M5 & 3.50 & 15.0 \\
\hline M6 & 3.50 & 20.0 \\
\hline M7 & 6.00 & 10.0 \\
\hline M8 & 6.00 & 15.0 \\
\hline M9 & 6.00 & 20.0 \\
\hline
\end{tabular}

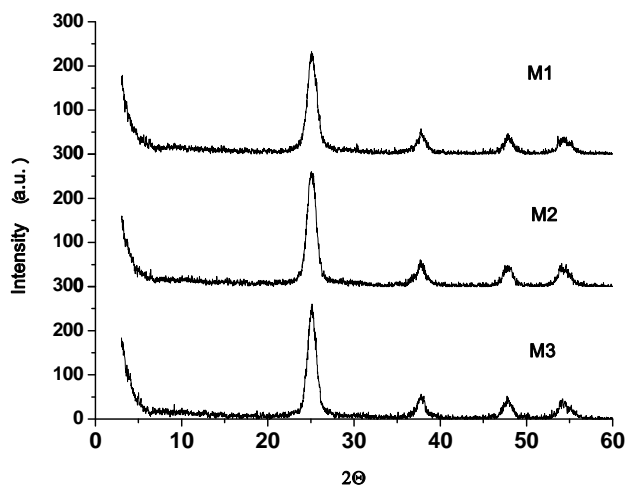

\section{RESULTS AND DISCUSSION}

Fig. (1) shows XRD spectrums of the synthesized $\mathrm{TiO}_{2}$ samples, four characteristic peaks of $\mathrm{TiO}_{2}$ are detected corresponding to the anatase phase [4,15]. As can be observed in Fig. (1), formation of the anatase phase and its crystallinity indicates a high dependence on the molar ratio water/TIOT; sample M5 with a quantity of water close to the stoichiometric ratio $\left(\mathrm{R}_{1 \text { (water/TIOT) }}=3.5\right.$ and $\mathrm{R}_{2(2 \text {-propanol/TIOT) }}=$ 15) shows the characteristic peak of the anatase phase with higher intensity and narrower. Upon augmenting the quantity of water above the stoichiometric ratio with $\mathrm{R}_{1 \text { (water/TIOT) }}=6$ and varying the molar ratio 2-propanol/TIOT with $\mathrm{R}_{2(2-}$ propanol/TIOT) $=10,15,20$ materials were obtained with a less intense peak in the anatase phase, see Fig. (1) for M7, M8 and M9; this is due to the strong reactions of hydrolysis. In Fig. (2), a decreasing of the peak intensity of the anatase phase in materials with quantities of water below the stoichiometric ratio $\left(\mathrm{R}_{1 \text { (water/TIOT) }}=0.17\right.$ and $\mathrm{R}_{2 \text { (2-propanol/TIOT) }}=$ 10) was observed and an amorphous material was obtained due to limited hydrolysis of the TIOT precursor $[3,16]$.

For the study of the optical properties of the synthesized $\mathrm{TiO}_{2}$ nanoparticles, the bandgap and the type of electronic transition were determined, which were calculated by means of the optic absorption spectrum [17]. When a semiconductor absorbs photons of energy larger than the gap of the semiconductor, an electron is transferred from the valence band to the conduction band where there occurs an abrupt increase in the absorbency of the material to the wavelength corresponding to the band gap energy. The relation of the
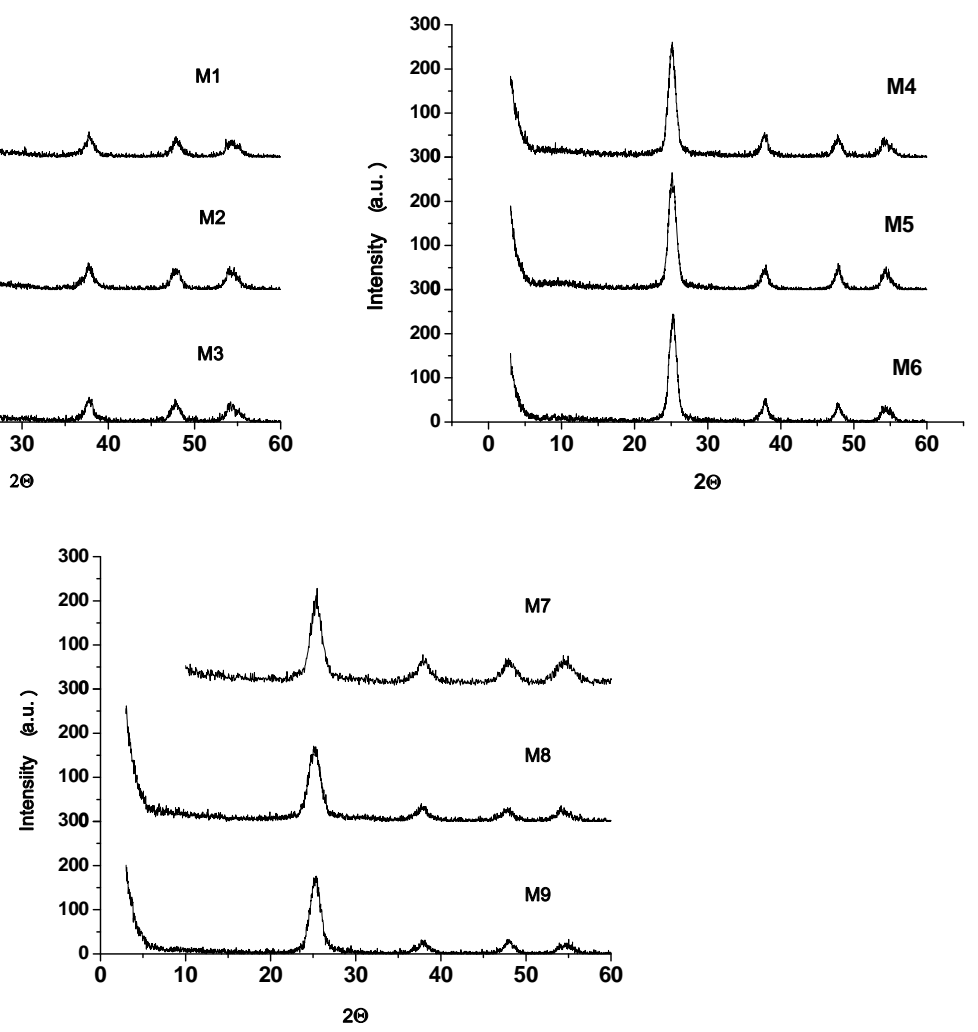

Fig. (1). XRD patterns of the $\mathrm{TiO}_{2}$ dioxides synthesized by sol-gel method and the hydrothermal treatment at different molar ratios of $\mathrm{R}_{1}$ (water/TIOT) and $\mathrm{R}_{2}$ (2-propanol/TIOT). 


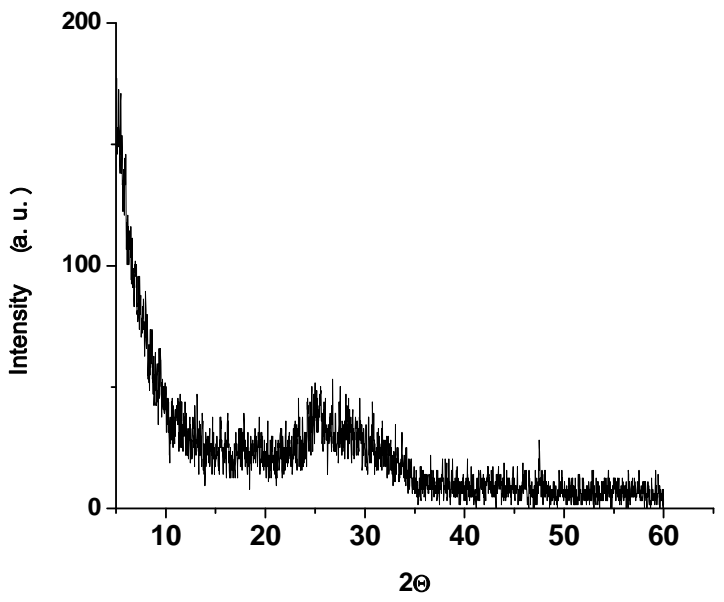

Fig. (2). XRD patterns of amorphous $\mathrm{TiO}_{2}$ at $\mathrm{R}_{1 \text { (water/TIOT) }}=0.17$, synthesized by sol-gel method and hydrothermal technique at $200^{\circ} \mathrm{C}$ for 2 hours.

absorption coefficient $(\alpha)$ to the incidental photon energy depends on the type of electronic transition. When, in this transition, the electron momentum is conserved, the transition is direct, but if the momentum does not conserve this transition it must be attended by a photon, this is an indirect transition [18,19]. To analyze the electronic properties of the $\mathrm{TiO}_{2}$ synthesized, the remission function of Kubelka-Munk was used F(R'œ) [20-24]:

$F\left(R^{\prime} \infty\right)=\frac{\left(1-R^{\prime}=\infty\right)^{2}}{2 R^{\prime} \infty}=\frac{\alpha}{S}$

where:

$R^{\prime}=0=\frac{R=0 \text { (muestra) }}{R=0(\text { estandar) }}$

$\mathrm{R} \infty\left(1 / 1_{0}\right)$ is the diffused reflectance of a given wavelength, of a dense layer of non transparent infinite material, $\alpha$ is the absorption coefficient $\left(\mathrm{cm}^{-1}\right)$ and $\mathrm{S}$ is the dispersion factor, which is independent of the wavelength for particles larger than $5 \mu \mathrm{m}$. $\alpha$ is related to the incidental photon energy by means of the following equation [25]:

$\alpha=A\left(E-E_{g}\right)^{\gamma}$

where: A is a constant that depends on the properties of the material, $\mathrm{E}$ is the photon energy, $\mathrm{E}_{\mathrm{g}}$ is the bandgap and $\gamma$ is a constant that can take different values depending on the type of electronic transition, for a permitted direct transition $\gamma=$ $1 / 2$, a prohibited direct transition $\gamma 3 / 2$, a permitted indirect transition $\gamma=2$ and for a prohibited indirect transition $\gamma=3$ $[26,27]$. Therefore:

$F\left(R^{\prime} \infty\right)=\frac{\alpha}{\mathrm{s}}=\frac{\mathrm{A}\left(E-E_{g}\right)^{\gamma}}{\mathrm{s}}$

$E(\mathrm{eV})=\frac{h C}{\lambda(\mathrm{nm})}=\frac{1236}{\lambda(\mathrm{nm})}$

$\mathrm{h}$ is the Planck constant and $\mathrm{C}$ is the light velocity. For a direct transition the equation is:

$F\left(R^{\prime} \infty\right)^{2}=\left(\frac{\mathrm{A}}{\mathrm{s}}\right)^{2}\left(\mathrm{E}-\mathrm{E}_{\mathrm{g}}\right)$

For an indirect transition the equation is:
$F\left(R^{\prime} \infty\right)^{\frac{1}{2}}=\left(\frac{\mathrm{A}}{\mathrm{s}}\right)^{\frac{1}{2}}\left(\mathrm{E}-\mathrm{E}_{\mathrm{g}}\right)$.

Figs. $(3,4)$ shows the $\mathrm{F}\left(\mathrm{R}^{\prime} \infty\right)^{2}$ vs $\mathrm{E}(\mathrm{eV})$ and $\mathrm{F}\left(\mathrm{R}^{\prime} \infty\right)^{1 / 2} v s$ $\mathrm{E}(\mathrm{eV})$ plots for the direct and indirect transitions, respectively, for the synthesized $\mathrm{TiO}_{2}$ samples, where the value of the band gap $\left(\mathrm{E}_{\mathrm{g}}\right)$ is obtained by extrapolating the linear part of the graphics to the axis of the abscissa. The $\mathrm{TiO}_{2}$ is activated with photons of energy of a longitude close to $400 \mathrm{~nm}$ which involves a band gap of $3.2 \mathrm{eV}$; the literature reports a $3.23 \mathrm{eV}$ value for anatase phase [28]. For the synthesized $\mathrm{TiO}_{2}$ samples the direct transition (Fig. 3) shows unrealistic bandgap values above $3.4 \mathrm{eV}$ reaching values of $3,63 \mathrm{eV}$, which were not expected for anatasa phase. The indirect type transition (Fig. 4) showing band gap values of between 3.13 to $3.27 \mathrm{eV}$, where sample M5 $\left(\mathrm{R}_{1 \text { (water/TIOT) }}=3.5\right.$ and $\left.\mathrm{R}_{2(2 \text {-propanol/TIOT }}=15\right)$ has a value of 3.24 $\mathrm{eV}$ as can be seen in Table 2. Therefore the $\mathrm{TiO}_{2}$ samples with anatase phase synthesized by the sol-gel method and a hydrothermal treatment follow an indirect type transition [7]. For the amorphous material $\left(\mathrm{R}_{1 \text { (water/TIOT) }}=0.17\right.$ and $\mathrm{R}_{2(2 \text { - }}$ propano/TIOT) $=10$ ) the bandgap values obtained were $3.75 \mathrm{eV}$ and $3.4 \mathrm{eV}$ for the direct and indirect transitions, respectively (Fig. 5). These bandgap values for the direct transition as well as for the indirect are quite high compared to the bandgap values for the crystalline phase. These results are in agreement with the work of Welte and co-workers [6] who used the sol-gel method at temperatures of $25^{\circ} \mathrm{C}, 200^{\circ} \mathrm{C}$ and $500^{\circ} \mathrm{C}$ to synthesize $\mathrm{TiO}_{2}$, obtaining amorphous, amorphouscrystalline and crystalline materials, respectively. For all of the $\mathrm{TiO}_{2}$ samples, the values of the direct transition were found to be above $3.5 \mathrm{eV}$. For crystalline material the direct transition showed a bandgap value of $3.23 \mathrm{eV}$. For amorphous material the indirect transition showed unrealistic bandgap value above $3.5 \mathrm{eV}$. This behavior suggests that the optical absorption technique is able to determine the type of morphology of the $\mathrm{TiO}_{2}$ materials [6]. Therefore, optical absorption measurements around $3 \mathrm{eV}$ to $4 \mathrm{eV}$ with plotting the direct transition and the indirect transition perform like an electronic fingerprint and determined if the materials are crystalline or amorphous. For amorphous materials the values of the bandgap are above $3.4 \mathrm{eV}$ independent of the transition type, which is in agreement with the XRD. The differences in bandgap values (Table 2), can be attributed to the crystalline size of the catalysts [8] which are in agreement with the diffractograms of the XRD analysis and are influenced by the molar ratio water/TIOT. When the hydrolysis reaction $\mathrm{Ti}(\mathrm{OR})_{4}+4 \mathrm{H}_{2} \mathrm{O} \rightarrow \mathrm{Ti}(\mathrm{OH})_{4}+4 \mathrm{R}(\mathrm{OH})$ is worked with molar ratios lower than those required for the stoichiometric ratio, water/TIOT $<4$, the hydrolysis between alkoxide and water is incomplete leaving a large quantity of non hydrolyzed alkoxy anions ( $\left.\mathrm{OR}^{-}\right)$that are absorbed onto the surface of the $\mathrm{TiO}_{2}$. These $\mathrm{OR}^{-}$influence the rate of $\mathrm{TiO}_{2}$ which favored the formation of a less crystalline anatase phase, the formation of particles with irregular shapes, distribution of large sizes, and low surface areas. An increase of water quantity above the stoichiometric ratio, water/TIOT $>4$, involves a strong reaction of nucleophilic replacement between water and the alkoxide molecules and more alkoxy $\left(\mathrm{OR}^{-}\right)$of the alkoxide precursor, these being substituted by hydroxyl groups of water involved in a reduction of the non hydrolyzed $\mathrm{OR}^{-}$diminishing the steric 

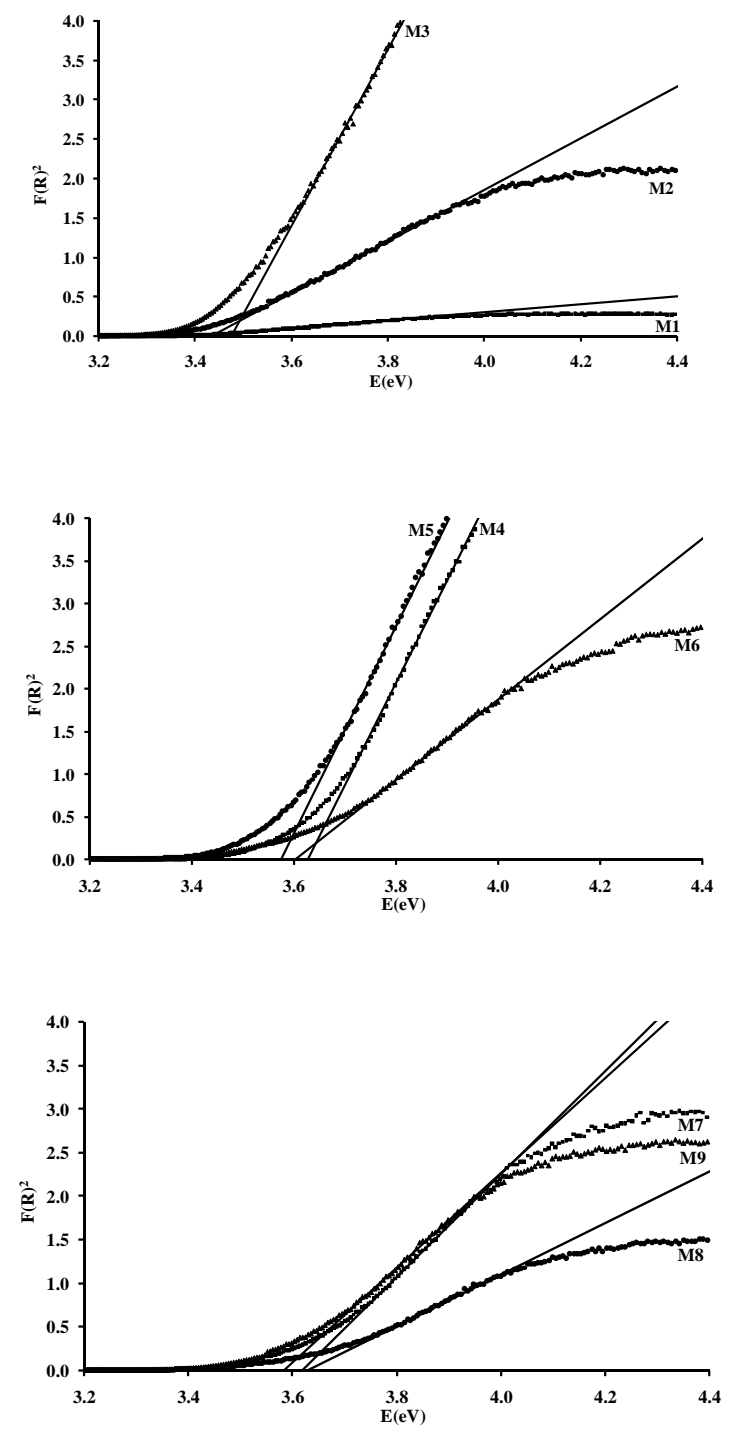

Fig. (3). Absorbance spectra for the direct electronic transition, $\mathrm{F}(\mathrm{R})^{2}$ vs $\mathrm{E}(\mathrm{eV})$ of the synthesized $\mathrm{TiO}_{2}$ samples with different

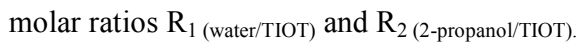

impediment, which reduces the anatase phase crystallization velocity or the formation of a high crystalline size and an increase of the surface area due to the empty spaces formed in the net structure $[3,13,29]$. As can be seen in Table $\mathbf{3}$, the increase in surface area $\left(\mathrm{S}_{\mathrm{BET}}\right)$ observed in the synthesized samples with more than 159.48 to $226.26 \mathrm{~m}^{2} \cdot \mathrm{g}^{-1}$ upon augmenting the water/TIOT molar ratio this is in agreement with previous works [30,31]. Fig. (6) shows diffused reflectance spectrums for the synthesized $\mathrm{TiO}_{2}$ samples and for Degussa P-25. The synthesized materials present absorption like that of the $\mathrm{TiO}_{2}$ Degussa P-25 with similar maximum wavelength. Thus, in this study the $\mathrm{TiO}_{2}$ preparation by means of sol-gel method and a hydrothermal treatment does not permit modification of the absorption spectrums toward the visible upon variation of the molar ration water/TIOT in the experiment design. The photocatalytic activity of the synthesized $\mathrm{TiO}_{2}$ samples and
$\mathrm{TiO}_{2}$ Degussa P-25 in the degradation of methyl orange is shown in Table 4. An increase in percentage of methyl orange degradation was observed upon increasing molar ratio water/TIOT up to a molar ratio $\mathrm{R}_{1 \text { (water/TIOT) }}=3.5$ and $\mathrm{R}_{2 \text { (2-propanol/TIOT) }}=15$ (sample M5), for molar ratios of water/TIOT lower than $\mathrm{R}_{1 \text { (water/TIOT) }}=3.5$ there is a decrease in the photocatalytic activity; this agrees with the XRD analysis when sample M5 has a peak with major intensity in the anatase phase, besides having an indirect bandgap of $3.24 \mathrm{eV}$.
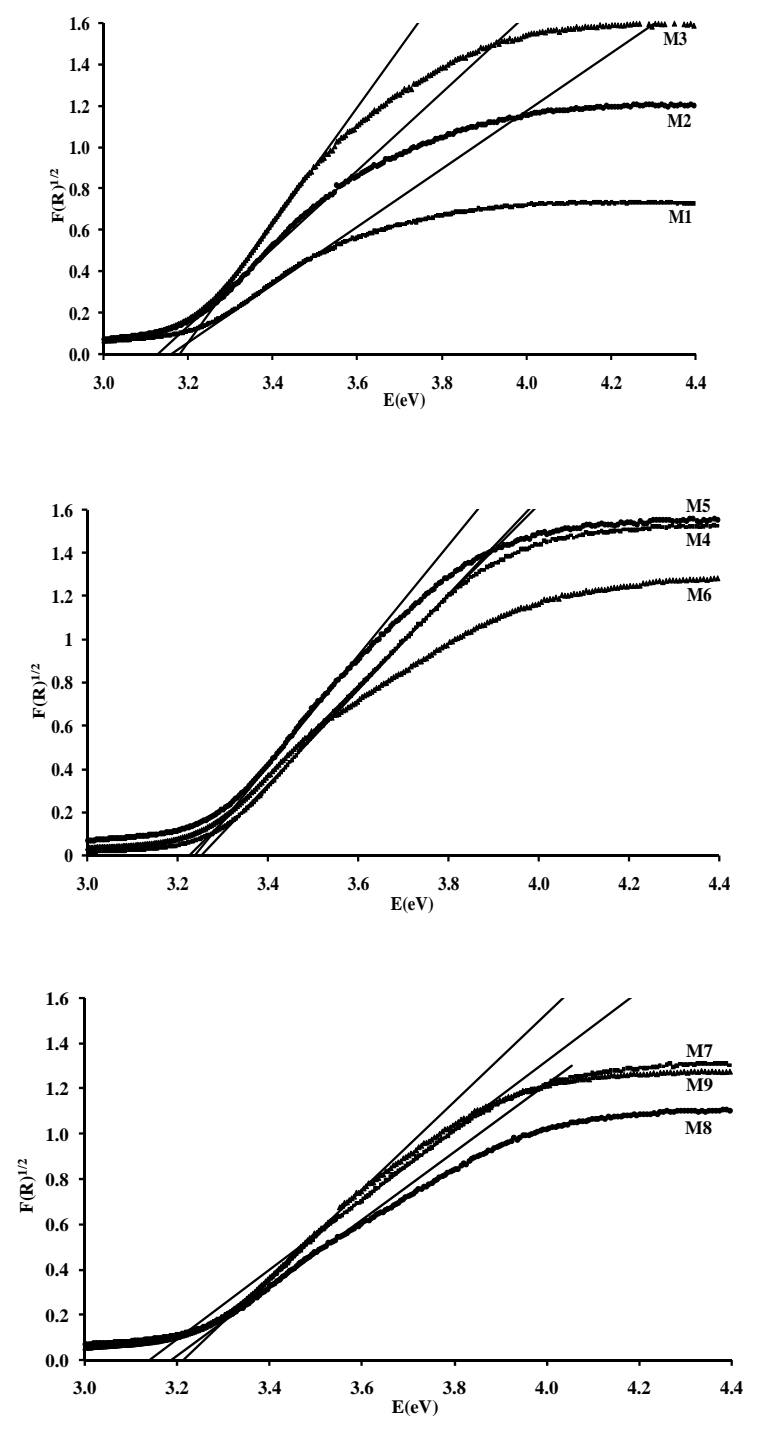

Fig. (4). Absorbance spectra for the indirect electronic transition $\mathrm{F}(\mathrm{R})^{1 / 2}$ vs $\mathrm{E}(\mathrm{eV})$ of the synthesized $\mathrm{TiO}_{2}$ samples with different molar ratios $\mathrm{R}_{1 \text { (water/TIOT) }}$ and $\mathrm{R}_{2 \text { (2-Propanol/TIOT). }}$.

\section{CONCLUSIONS}

The sol-gel method with a hydrothermal treatment at a temperature of $200^{\circ} \mathrm{C}$ for two hours using TIOT as a precursor and 2-propanol as solvent permitted titanium dioxide nanoparticles to be synthesized in the anatase phase, as well as high surface areas, which show a gradual increase 
(a)

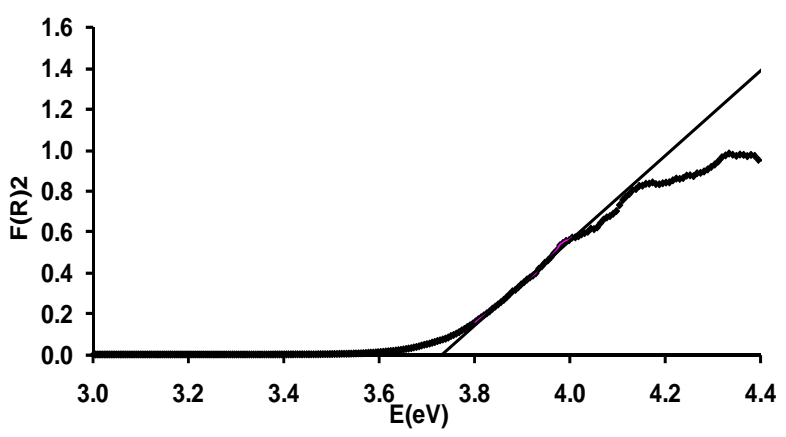

(b)

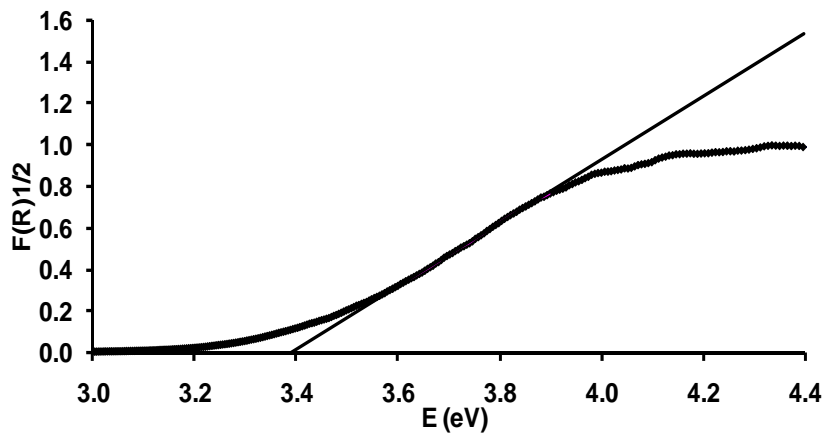

Fig. (5). Absorbance spectra for amorphous $\mathrm{TiO}_{2}$ samples at $\mathrm{R}_{1 \text { (water/TIOT) }}=0.17$ : a) direct electronic transition type and b) Indirect transition type.

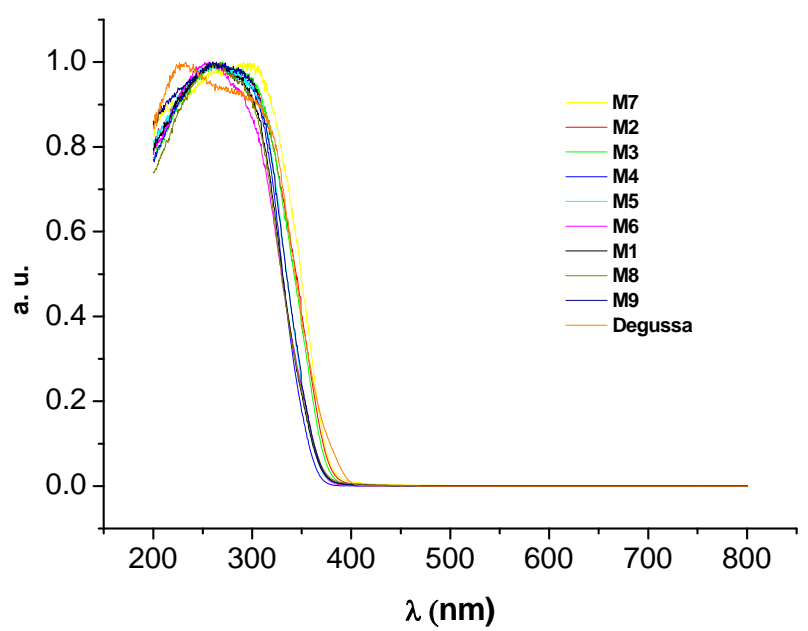

Fig. (6). Diffusion reflectance spectrums of the synthesized $\mathrm{TiO}_{2}$ samples.

of over 159.48 to $226.26 \mathrm{~m}^{2} \mathrm{~g}^{-1}$. These materials show an indirect type band gap close to those reported in the bibliography of $3.23 \mathrm{eV}$ for the anatase phase. Besides, found optical absorption shows that the direct bandgap verses indirect bandgap permits the determination of the crystillinity of a material; for an amorphous material the band gap is greater than $3.4 \mathrm{eV}$ independent of the transition types. All the properties of the synthesized materials
Table 2. Direct and Indirect Bandgap Transitions for Synthesized $\mathrm{TiO}_{2}$ Samples

\begin{tabular}{|c|c|c|}
\hline \multirow{2}{*}{ Sample } & \multicolumn{2}{|c|}{ Bandgap (eV) } \\
\cline { 2 - 3 } & Direct & Indirect \\
\hline \hline M1 & 3.40 & 3.15 \\
\hline M2 & 3.43 & 3.13 \\
\hline M3 & 3.47 & 3.18 \\
\hline M4 & 3.63 & 3.25 \\
\hline M5 & 3.58 & 3.24 \\
\hline M6 & 3.60 & 3.27 \\
\hline M7 & 3.62 & 3.22 \\
\hline M8 & 3.63 & 3.19 \\
\hline M9 & 3.58 & 3.14 \\
\hline
\end{tabular}

Table 3. Superficial Area of $\mathrm{TiO}_{2}$ Samples Synthesized the Sol-Gel Method and the Hydrothermal Treatment

\begin{tabular}{|c|c|}
\hline Muestra & $\mathbf{S}_{\text {BET }}\left(\mathbf{m}^{2} \cdot \mathbf{g}^{-1}\right)$ \\
\hline \hline M1 & 159.48 \\
\hline M2 & 162.30 \\
\hline M3 & 169.11 \\
\hline M4 & 175.09 \\
\hline M5 & 177.65 \\
\hline M6 & 179.11 \\
\hline M7 & 203.33 \\
\hline M8 & 219.86 \\
\hline M9 & 226.26 \\
Degussa & 48.90 \\
\hline
\end{tabular}

Table 4. Photocatalytic Degradation of a Methyl Orange Solution (20ppm) with the Synthesized $\mathrm{TiO}_{2}$ Samples $\left(150 \mathrm{pm}\right.$ of $\mathrm{TiO}_{2}$ ), Adsorption Time 1 Hour, Degradation 7 Hours

\begin{tabular}{|c|c|}
\hline Sample & \% Degradation \\
\hline \hline M1 & 60.86 \\
\hline M2 & 62.43 \\
\hline M3 & 60.69 \\
\hline M4 & 79.89 \\
\hline M5 & 100.0 \\
\hline M6 & 81.11 \\
\hline M7 & 75.16 \\
\hline M8 & 61.55 \\
\hline M9 & 58.83 \\
Degussa & 100.0 \\
\hline
\end{tabular}


depended on the $\mathrm{R}_{1 \text { (water/TIOT) }}$ molar ratio where the catalyst with the greater photocatalytic activity has the molar ratios: $\mathrm{R}_{1 \text { (water/TIOT) }}=3.5$ and $\mathrm{R}_{2(2 \text {-propano/ } / \mathrm{TIOT})}=15$.

\section{ACKNOWLEDGEMENT}

The authors wish to thank the financial support to the University of Antioquia through the "Estrategia de Sostenibilidad de Grupos 2009-2010" program.

\section{REFERENCES}

[1] Reddy K, Manorama S, Redd A. Bandgap studies on anatase titanium dioxide nanoparticles. Mater Chem Phys 2002; 78: 23945 .

[2] Jing 1, Li S, Song S, Xue L, Fu H. Investigation on the electron transfer between anatase and rutile in nano-sized $\mathrm{TiO}_{2}$ by means of surface photovoltage technique and its effects on the photocatalytic activity. Solar Energy Mater Solar Cells 2008; 92: 1030-6.

[3] Wang G. Hydrothermal synthesis and photocatalytic activity of nanocrystalline $\mathrm{TiO}_{2}$ powders in ethanol-water mixed solutions. $\mathrm{J}$ Mol Catal A: Chem 2007; 274: 185-91

[4] Sahni S, Reddy B, Murty B. Influence parameters on the synthesis of nano-titania by sol-gel route. Mater Sci Eng A 2007; 452-453: 758-62.

[5] Francisco M. y Mastelaro V. Inhibition of the anatase-rutile phase transformation with addition of $\mathrm{CeO}_{2}$ to $\mathrm{CuO}-\mathrm{TiO}_{2}$ system: Raman spectroscopy, X-ray diffraction, and textural studies. Chem Mater 2002; 14 (6): 2514-8.

[6] Welte A, Waldauf C, Brabec C, Wellmann P. Application of optical for the investigation of electronic and structural properties of sol-gel processed $\mathrm{TiO}_{2}$ films. Thin Solid Films 2008; 516: 72569 .

[7] Monllor-Satoca D, Gomez R, González-Hidalgo M, Salvador P. The "Diret-Indirect" model: An Alternative kinetic approach in heterogeneous photocatalysis based on the degree of interaction of dissolved pollutant species with the semiconductor surface. Catal Today 2007; 129: 247-55

[8] Hidalgo M, Aguilar M, Maicu M, Navio J, Colon G. Hydrothermal preparation of highly photoactive $\mathrm{TiO}_{2}$ nanoparticles. Catal Today 2007; 129: 50-8.

[9] Hossain F, Sheppard L, Nowotny J, Murch G. Optical properties of anatasa and rutile titanium dioxide: $\mathrm{Ab}$ initio calculations for pure and anion-doped material. J Phys Chem Solids 2008; 69: 1820-8.

[10] Marín JM, Restrepo G, Rios LA, Navío JA. Nueva ruta de síntesis para el dióxido de titanio. Rev Colomb Fís 2005; 37: 78-81.

[11] Su C, Tseng C, Chen L, You B, Hsu B, Chen S. Sol hydrothermal and photocatalysis of titanium dioxide. Thin Solid Films 2006; 498: 259-65.

[12] Wen B, Liu C, Liu Y. optimization of the preparation methods synthesis of meso structures $\mathrm{TiO}_{2}$ with high photocatalytic activities. J Photochem Photobiol A: Chem 2005; 173: 7-12.

[13] Yu J, Wang G, Cheng B, Zhou M. Effects of hydrothermal temperature and time on the photocatalytic activity and microstructures of bimodal mesoporous $\mathrm{TiO}_{2}$ powders. Appl Catal B: Environ 2007; 69: 171-80.

[14] Zhu J, Yang J, Bian Z, et al. Nanocrystaline anatase $\mathrm{TiO}_{2}$ photocatalysis prepared via a facile low temperature nonhydrolitic sol-gel reaction of $\mathrm{TiCl}_{4}$ and benzyl alcohol. Appl Catal B: Environ 2007; 76: 82-91.

[15] Liu G, Jin Z, Wang T, Liu Z. Anatase $\mathrm{TiO}_{2}$ porous thin films prepared by sol-gel method using CTAB surfactant. J Sol-Gel Tech 2007; 41: 49-55.

[16] $\mathrm{Yu} \mathrm{H}$, Wang S. effects of water content and $\mathrm{pH}$ on gel-derived $\mathrm{TiO}_{2}-\mathrm{SiO}_{2}$. J Non-Crystal Solids 2000; 261: 260-7.

[17] Essick J, Mather R. Characterization of a bulk semiconductor's band gap via near-absorption edge optical transmission experiment. Am J Phys 1993; 61: 646-9.

[18] Willardson R, Beer A. Optical Properties of III-V Compounds. Academic Press New York 1967; pp. 318-400.

[19] Dressel M, Gruner G. Electrodynamics of Solids Optical Properties of Electron in Matter. Cambridge University Press 2002; pp. 15965 .

[20] Kottim G. Reflectance spectroscopy. Springer Verlag. New York 1969.

[21] Tandon S, Gupta J. Measurement of forbidden energy gap of semiconductors by diffuse reflectance technique. Phys Stat Sol $1970 ; 38: 363-7$.

[22] Wendlandt W, Hecht H. Reflectance Spectroscopy. Wiley Interscience New York 1966.

[23] Sreen K, Poulose C, Unni B. Colored cool colorants based on rare earth metal ions. Solar Energy Mater Solar Cells 2008; 92: 1462-7.

[24] Bagheri-Mohagheghi M, Shahtahmasebi N, Alinejad M. The effect of the post-annealing temperature on the nano-structure and energy band gap of $\mathrm{SnO}_{2}$ semiconducting oxide nano-particles synthesized by polymerizing-complexing Sol-gel method. Phys B: Condensed Matter 2008; 403: 2431-7.

[25] Ting C, Chen S. Structural evolution and optical properties of $\mathrm{TiO}_{2}$ thin films prepared by thermal oxidation of sputtered Ti films. J Appl Phys 2000; 88: 4628-33.

[26] López S, Castillo S, Chávez J, Díaz K. Síntesis y caracterización óptica, eléctrica y estructural de películas delgadas de CS depositadas por el método PECVD. Materia 2003; 8: 341-9.

[27] Oliva F, Avalle L, Santos E, Camara O. Photoelectrochemical characterization of nanocrystalline $\mathrm{TiO}_{2}$ films on titanium substrates. J Photochem Photobiol A: Chem 2002; 146: 175-88.

[28] Litter M. Heterogeneous photocatalysis transition metal ions in photocatalytic systems. Appl Catal B: Environ 1999; 23: 89-114.

[29] Venkatachalam N, Palanichamy M, Murugesan V. Sol-gel preparation and characterization of nanosize $\mathrm{TiO}_{2}$ : Its photocatalytic performance. Mater Chem Phys 2007; 104: 457-9.

[30] Kolen'ko Y, Churagulov B, Kunst M, Mazerolles L, Colbeau Justin. Photocatalytic properties of titania powders prepared by hydrothermal method. Appl Catal B: Environ 2004; 54: 51-8.

[31] Kominami G, Kato J, Takada Y, et al. Novel synthesis of microcrystalline titanium(IV) oxide having high thermal stability and ultra-high photocatalytic activity: thermal decomposition of titanium(IV) alkoxide in organic solvents. Catal Lett 1997; 46: 23540 . 